Sains Malaysiana 50(9)(2021): 2743-2754

http://doi.org/10.17576/jsm-2021-5009-20

\title{
The Effects of In-Process Cooling during Friction Stir Welding of 7475 Aluminium Alloy
}

(Kesan Proses Penyejukan Dalam semasa Kimpalan Kacauan Geseran Aloi Aluminium 7475)

\author{
Ashish Jacob, Sachin Maheshwari, Arshad Noor Siddiquee, Abdulrahman Al-Ahmari, Mustufa \\ HAider Abidi*, SERGey Konovalov \& Xizhang Chen
}

\section{ABSTRACT}

Certain age hardenable alloys such as AA7475 cannot be joined with perfection using fusion welding techniques. This requires non-conventional welding technique such as friction stir welding process to join these 'difficult to weld'alloys. In this study, three different cooling conditions i.e. cryogenic, sub-zero, and zero-degree Celsius temperature conditions have been analyzed to understand its impact on the welding process. In-process cooling was found to behave effectively and also enhanced the mechanical properties of the welded joints. A stable microstructure was clearly seen in the images observed under the metallurgical microscope. The weld efficiencies were found to be good in each of the samples which are indicative of a strong metallic joint. The effective cooling conditions employed had an overall positive impact on the joint.

Keywords: AA-7475; age-hardenable; friction stir welding; in-process cooling; joints cooling; liquid nitrogen

\section{ABSTRAK}

Aloi boleh dikeraskan seperti AA7475 sukar disambung dengan sempurna melalui teknik kimpalan lakuran. Ia memerlukan teknik kimpalan bukan konvensional seperti proses kimpalan kacauan geseran untuk menyambung aloi tersebut. Dalam kajian ini, tiga keadaan penyejukan yang berbeza, iaitu keadaan suhu kriogenik, sub-sifar dan sifar darjah Celsius telah dianalisis untuk memahami kesannya ke atas proses kimpalan. Proses penyejukan dalam didapati berkesan dan mempertingkatkan sifat mekanik sambungan terkimpal. Mikrostruktur yang stabil telah diperhati di bawah mikroskop metalurgi. Keberkesanan kimpalan yang baik telah diperhati pada setiap sampel yang menunjukkan sambungan logam yang kuat. Keadaan sejuk semasa kimpalan telah memberi kesan positif ke atas sambungan yang dilakukan.

Kata kunci: AA-7475; cecair nitrogen; kimpalan pengacauan geseran; penyejukan dalam proses; penyejukan sambungan

\section{INTRODUCTION}

One of the primary objectives in the transportation sector in general and particularly in aerospace is to reduce weight which translate into fuel efficiency and reduced carbon footprint. Need for high strength light weight structures has attracted use of aluminum alloys. AA2 xxx and AA7Xxx series alloys are regarded as high strength alloys which get strengthened by age-hardening. AA7475 is among one of the largest used alloys in aircraft and aerospace applications. The size and complexities of the airframe structures necessitate the assembly of structural members through joining. Presently, standard riveted joints are being fast replaced by one of the recent solid state joining technique known as Friction Stir Welding (FSW). Fusion welding techniques have been attempted but have never been successful in achieving higher weld efficiencies and have not been able to provide a clean 
weld i.e. a weld with no defects (Çam \& İpekoğlu 2017). The alloys of AA7xxx series are usually regarded as unweldable because of serious strength reduction of joint due to over-aging caused by welding heat. The FSW is performed at considerably low temperature/heat in comparison to fusion welding and during FSW the material does not melt (Patel et al. 2019). Even if the FSW is not performed with diligence, the joint efficiency of AA7xxx series alloys may drop beyond acceptable limit. The care during welding of AA7 $\mathrm{xxx}$ should be taken to control the excessive rise or temperature, avoid defect formation and produce sound joint.

The FSW utilizes a non-consumable cylindrical tool with shoulder and a pin at one end. The tool while rotating about its axis plunges into the faying surface till it contacts the surface. The friction between the surface and shoulder provides heat input and softens the materials. The tool is next made to traverse along the joint-line. The rotating-cum-traversing action produced mixing of the materials being joined via stirring and joint is made. The FSW joint has characteristic microstructural zones with the one which is directly stirred is known as stir zone (SZ). During the FSW severe plastic deformation (SPD) occurs due to stirring action in SZ of the joints (Patel et al. 2019) which is responsible for ultrafine grains in this zone.

Çevik et al. (2016), found that arc welding results in undesirable microstructure including hot cracking. They noted that AA7xxx series possesses very high crack sensitivity. Attempts have been made to join AA7475 sheets by using laser welding. Weston and Wallach (1998), performed pulsed Nd:YAG laser welding and achieved joint efficiency of only $26 \%$ (with ultimate tensile strength (UTS) of the joint equal to $126 \mathrm{MPa}$ ). Çam et al. (2014) tried cooling the weld zone during FSW of AA6061. The authors reported that an effective cooling medium can attain higher joint strength, which opened doors for a more systematic approach to achieve greater strengths using appropriate cooling medium.

Restricting temperature below characteristic values can effectively control the process of precipitate coarsening which causes softening in age-hardening alloys. Most of aging sequences in age-hardenable alloys like those of 7xxx series start with formation of GP (Guinier Preston) zones (Berg et al. 2001). If the age-hardened alloys are not cooled below the solvus temperature quickly it could lead to excessive dissolution of the strengthening precipitates which is catastrophic if the idea is to have an alloy that is to be welded to achieve maximum strength. When an effective cooling medium is used during FSW would limit the dissolution and coarsening of the strengthening precipitates present in the joint.

FSW joints have very good mechanical properties and especially in case of age-hardened alloys the joint strength is far better than the fusion welded joints (Kumar et al. 2019). While fusion weld of age-hardened alloy joint has poor joint efficiency (35\%), the same for the FSWed joint can be enhanced to double. The use of cooling during FSW of age-hardened alloys can further improve the joint efficiency. An investigation on FSW of age-hardened AA2219-T6 demonstrated that the strength of FSW joint increased from 324 to $341 \mathrm{MPa}$ when the FSW was performed under cooling medium (Zhang et al. 2011), Kishta and Darras (2014) compared the properties of normal FSW joints with those performed submerged under water. They demonstrated that the strength of the under-water FSW joint was greater than the base metal (BM) and that of normal FSW joint.

Mofid et al. (2012) joined AA5083 with AZ31 under normal condition with cooling under water and liquid nitrogen. The authors reported highest joint strength with water cooling whereas the poorest joint strength was achieved for normal FSW joints. A research study (Hofmann \& Vecchio 2007) demonstrated that use of cooling media can also achieve significant grain refinement in case of friction stir processing (FSP). Nelson et al. (2003) demonstrated 10\% increase in the strength of age-hardening alloy AA7075 for submerged FSWed joint in comparison to normal FSW.

Sakurada et al. (2002), used submersion technique on AA6061 and showed a reduction in peak temperature and enhanced joint efficiency. They reported a joint efficiency of $86 \%$ which was way higher in comparison to the plates joined without any cooling. Hosseini and Danesh Manesh (2010) studied the microstructure of FSWed AA1050 using water as a quenching agent. They observed extremely fine grains (smaller than the grains found in normal FSW) and even smaller sub-grains in SZ region of the joint. An increment in the yield strength was evident due to the presence of small grains and as per the Hall-Petch relationship. The effect of water cooling on the thermal profile during FSW and demonstrated that the temperature near tool were significantly less than that in case of normal FSW (Fratini et al. 2010). $\mathrm{Xu}$ et al. (2012), through their micro-structural studies 
demonstrated that the strength and ductility of the FSW joint both increased when quenching media was used. The authors also demonstrated that the coarsening of grain in HAZ was also significantly reduced.

Sharma et al. (2012) welded AA7039 via FSW and noted that use of cooling prevented coarsening of alpha Al grains. They also observed excessive coarsening (approximately 1.7 times greater) of the precipitates during welding without cooling medium. The same has also been confirmed by several other investigations (Baillie et al. 2015; Huang et al. 2016; Jariyaboon et al. 2009; Liu et al. 2019; Liu et al. 2018; Miura et al. 2018; $\mathrm{Xu}$ et al. 2015; Yi et al. 2016).

While most studies compared air, water, and liquid nitrogen as cooling agents, Jacob et al. (2018) used liquid nitrogen and ice water slush and showed significant rise in tensile properties and a very stable microstructure in weld ice-water-slush. It is evident that the rate can be controlled by using appropriate cooling medium. The rate of cooling also controls the weld temperature, grain size, and the precipitate state. All these are critical to the joint quality. Also, most work utilized, air, water and liquid nitrogen as cooling medium. Therefore, to further extend the research work in the field, in this study, three different cooling conditions i.e. cryogenic, sub-zero, and zero-degree Celsius temperature conditions have been used to understand its impact on the welding process.

\section{MATERIALS AND METHODS}

Each of the FSW experiments was performed on a modified vertical milling machine. A well designed fixture was used to perform the welding operation. This multipurpose fixture can perform both submerged and normal FSW. Slots were machined to accommodate acrylic sheets that are used to hold the liquid for submerged FSW processes as shown in Figure 1.

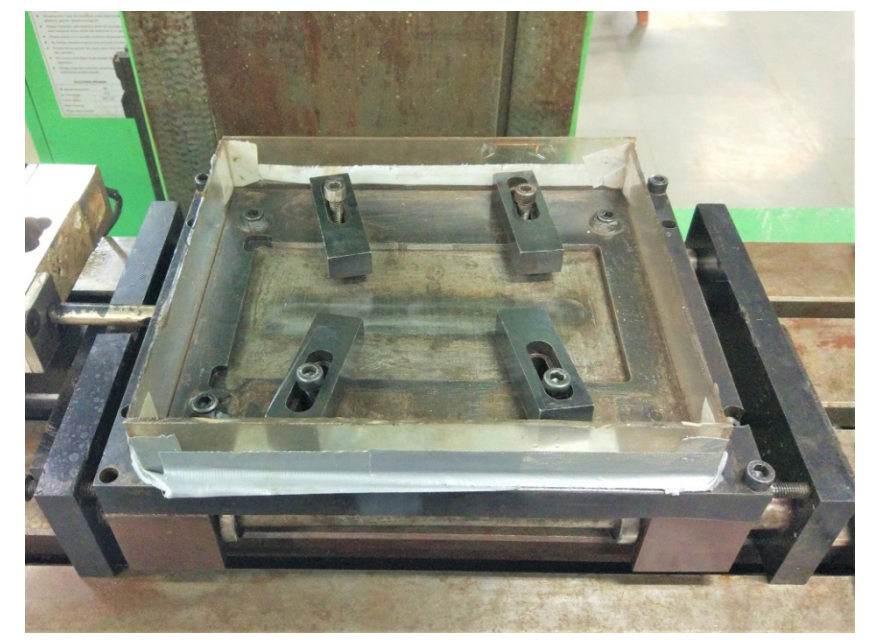

FIGURE 1. FSW fixture setup for experiments

The elemental composition of AA7475 aluminium alloy used in this study is shown in Table 1. This alloy is a high strength age-hardenable alloy with aircraft/ aerospace applications. The $2.1 \mathrm{~mm}$ thick AA7475 sheets were machined to $150 \mathrm{~mm}$ (long) and $50 \mathrm{~mm}$ (wide) size for welding. Three runs were performed under three cooling conditions. Three different cooling conditions are used namely; cryogenic (liquid nitrogen), 
refrigeration (crushed ice and rock salt mixture) and zero degree Celsius (ice-water-slush). The temperatures of each of the cooling conditions are shown in Table 3. The experimental plan for the runs is shown in Table 2 . The friction stir welding condition were optimized via a thorough experiment regime for underwater FSW. The FSW tool made from $\mathrm{H} 13$ steel having $12 \mathrm{~mm}$ shoulder diameter and cylindrical pin $2.1 \mathrm{~mm}$ length was used.
The samples for microstructural analysis, microhardness test and tensile tests were machined by using wire electric discharge machine (WEDM). The sample for microstructural examination were polished following standard microstructural sample preparation procedures. The micro-hardness tests were performed at $1 \mathrm{~N}$ load and a dwell of $10 \mathrm{~s}$. The tensile test samples were prepared in accordance with ASTM E8. The tensile tests were performed on a tensometer with a computer interface at a cross head speed of $2 \mathrm{~mm}$ per minute.

TABLE 1. Weight percentage of the base metal

\begin{tabular}{cc}
\hline Element & Weight (\%) \\
\hline $\mathrm{Al}$ & 90.19 \\
$\mathrm{Zn}$ & 6.2 \\
$\mathrm{Cr}$ & 1.9 \\
$\mathrm{Cu}$ & 0.18 \\
$\mathrm{Fe}$ & 1.2 \\
$\mathrm{Mg}$ & 0.12 \\
$\mathrm{Mn}$ & 0.06 \\
$\mathrm{Si}$ & 0.1 \\
$\mathrm{Ti}$ & 0.05 \\
\hline
\end{tabular}

TABLE 2. Experimental plan

\begin{tabular}{cccc}
\hline Run number & $\begin{array}{c}\text { Rotational speed } \\
(\mathrm{rpm})\end{array}$ & $\begin{array}{c}\text { Welding speed } \\
(\mathrm{mm} / \mathrm{min})\end{array}$ & Cooling condition \\
\hline 1 & 900 & 80 & Liquid nitrogen \\
2 & 900 & 80 & Crushed ice and rock salt \\
3 & 900 & 80 & Ice water slush \\
\hline
\end{tabular}


TABLE 3. Temperature for each cooling condition

\begin{tabular}{cccc}
\hline Run number & Cooling condition & Temperature $\left({ }^{\circ} \mathrm{C}\right)$ & Cooling category \\
\hline 1 & Liquid nitrogen & -198 & Cryogenic \\
2 & Crushed ice and rock salt & -35 & Refrigerating \\
3 & Ice water slush & 0 & Zero Degrees \\
\hline
\end{tabular}

\section{RESULTS AND DISCUSSION}

\section{WELD APPEARANCE AND MICRO-HARDNESS}

All welded samples were free of all visible defect and possessed flash free clear ripples (Figure 2(a). Among all samples however, Sample 2 showed coarser ripple appearance. This may be attributed to the fact that the pieces of rock-salt and ice in the mixture were relatively large and the mixture is corrosive. Backside of all the welds clear possessed uniform seam and clear of any excessive or lack of penetration. In general, if such issues occur, the welded plates are discarded and a new experiment has to be performed. The examination of transverse cross-sections also did not possess any void or tunnel defect.
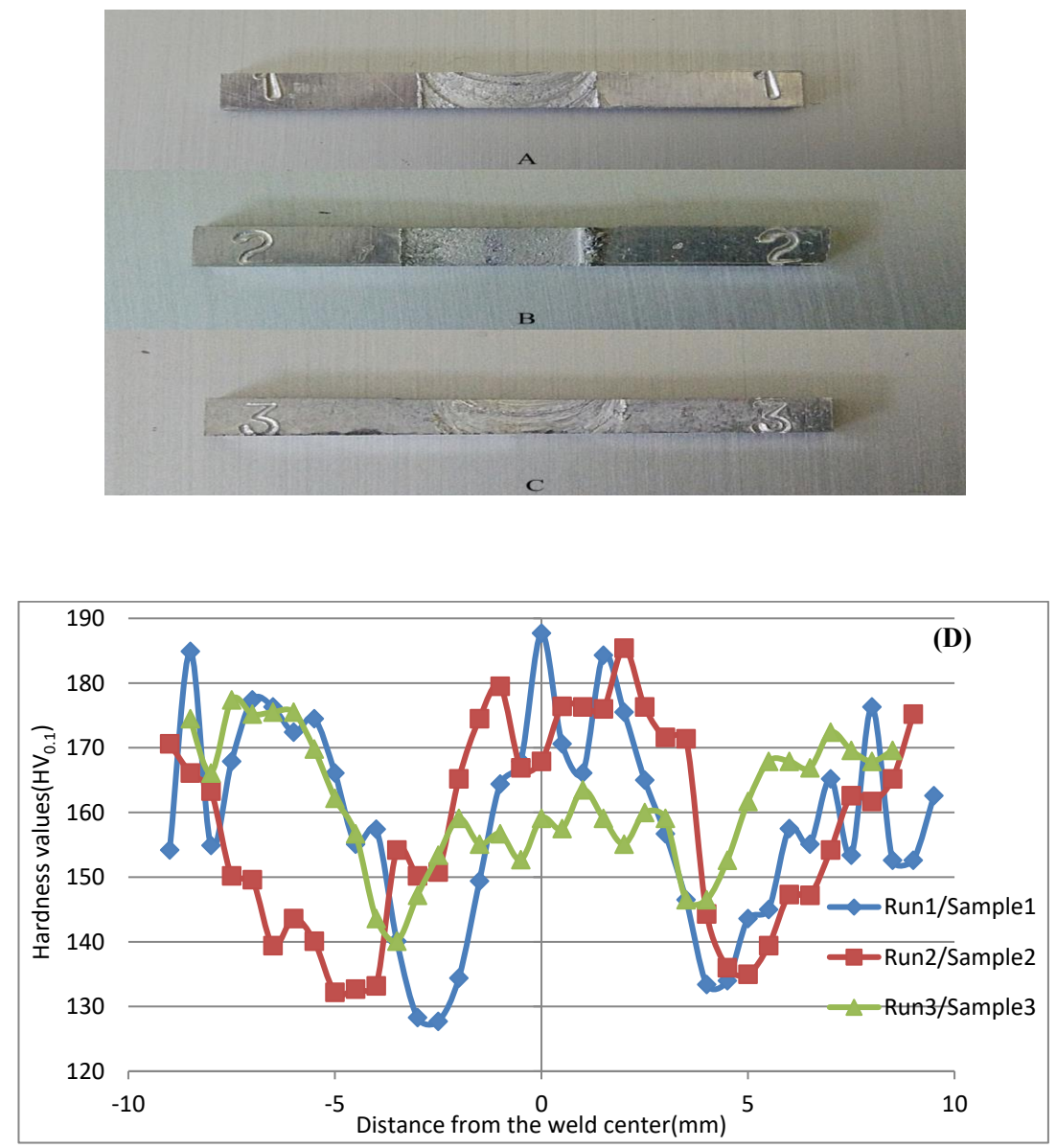

FIGURE 2. Weld appearance for (A) run 1 (B) run2 (C) run3 (D)

Micro hardness graph for samples 1, 2, and 3 
Figure 2(D) shows the micro-hardness plots traced for each sample from the AS to the RS. The microhardness plots follow the characteristic ' $W$ ' shaped profile with highest values is seen in the SZ region for all the cooling conditions. The plots show that the plot for the samples which were welded with ice water slush show the lowest hardness values in SZ. The characteristic ' $W$ ' shaped profile in all three cooling conditions indicates that the cooling conditions do not alter the characteristic microstructure and associated property evolution across the FSW weld cross section.

SZ showed higher hardness values in comparison to all other weld zones. In case of sample-1, the average hardness value in the SZ region was found to be 166.7HV. In the TMAZ, the average hardness value was found to be $138.37 \mathrm{HV}$. While the HAZ showed the average hardness value to be 165.1 .

The second run was performed using ice and rock salt. The average micro-hardness values in the SZ region for sample-2 is found to be $154.67 \mathrm{HV}$. There was an observable loss of hardness at the SZ and TMAZ interface. TMAZ showed average hardness value of $150.72 \mathrm{HV}$. The average hardness value in HAZ region was found to be $136.36 \mathrm{HV}$. Each of these values are also shown in Table 4.

TABLE 4. Micro-hardness values

\begin{tabular}{cccccc}
\hline Samples & $\begin{array}{c}\text { SZ region } \\
(\mathrm{HV})\end{array}$ & $\begin{array}{c}\text { TMAZ } \\
(\text { advancing side }) \\
(\mathrm{HV})\end{array}$ & $\begin{array}{c}\text { TMAZ } \\
\text { (retreating side) }\end{array}$ & $\begin{array}{c}\text { HAZ } \\
\text { (advancing side) } \\
(\mathrm{HV})\end{array}$ & $\begin{array}{c}\text { HAZ } \\
\text { (retreating side) } \\
(\text { HV) }\end{array}$ \\
\hline 1 & 166.7 & 138.37 & 150.4 & 165.1 & 142.7 \\
2 & 154.67 & 150.72 & 169.8 & 136.36 & 140.4 \\
3 & 157.54 & 148.68 & 153.44 & 161.56 & 159.32 \\
\hline
\end{tabular}

Ice water slush experiment altogether showed a completely different graph profile. The hardness value in SZ region of the weld was found to be $157.54 \mathrm{HV}$. The micro hardness graphs showed softening in the SZ region. There is very little drop in the hardness values of TMAZ region. HAZ showed higher hardness value of $161.56 \mathrm{HV}$ in comparison to other zones. Hardness in TMAZ was found to be $148.68 \mathrm{HV}$. In sample 3 of run 3, the hardness values showed a much lower drop in comparison to the previous samples. A comparison of the plots indicates that while the peak hardness in case of cryogenic cooling is highest, the drop in the hardness at TMAZ region is also highest for this condition. The hardness bottoms out at the TMAZ regions due to the fact that there is a sharp change in temperature from the SZ to TMAZ. In case of liquid nitrogen ( $\mathrm{LN}$ ) cooling the material being stirred is submerged under the shoulder and the effect of LN is very less, but outside the shoulder the cooling is very fast.
This created a sharp variation in the thermal profile and resulted in the sharpest drop in hardness value in case of sample-1. Among all three cooling conditions, the cooling rate in case of sample-3 was most moderate and the temperature profiles would have been stabilized resulting the more stabilized micro-hardness plot for sample-3.

\section{MICROSTRUCTURAL EVOLUTION}

Three zones are well associated with the FSWed joints which are Thermo-mechanically affected zone, Heat affected zone, and Stir Zone. The distinctive observations have been made with regard to each zone which could be seen in Table 5. The base metal was also observed under the metallurgical microscope and Figure 3 shows its microstructure. The BM microstructure could be useful in comparing how the grain morphology changes in each of these zone viz-a-viz original BM morphology. 


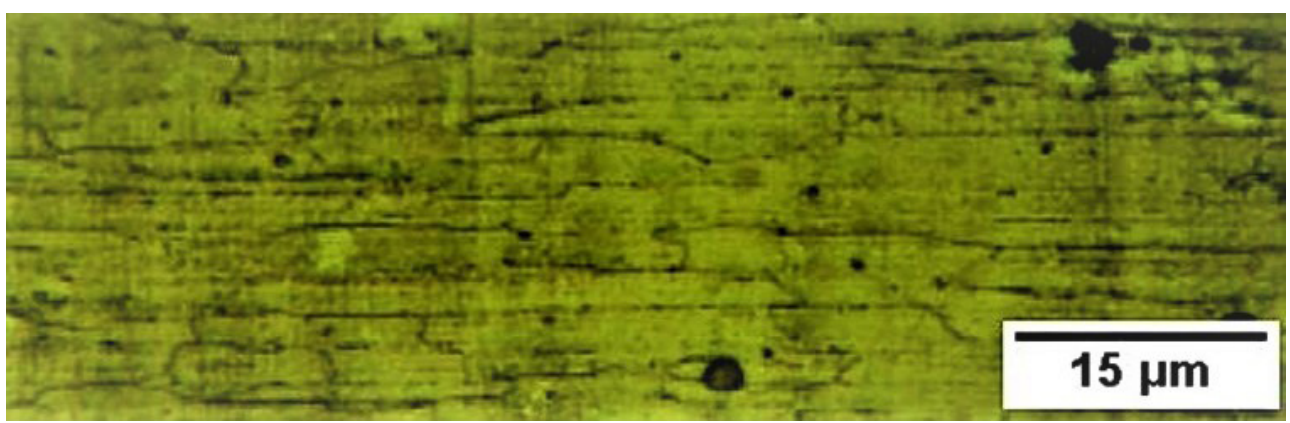

FIGURE 3. Microstructure of the base metal at 40X magnification

TABLE 5. Average grain sizes

\begin{tabular}{cccccc}
\hline Samples & SZ region $(\mu \mathrm{m})$ & $\begin{array}{c}\text { TMAZ } \\
(\text { advancing side }) \\
(\mu \mathrm{m})\end{array}$ & $\begin{array}{c}\text { TMAZ } \\
(\text { retreating side }) \\
(\mu \mathrm{m})\end{array}$ & $\begin{array}{c}\text { HAZ } \\
\text { (advancing side) } \\
(\mu \mathrm{m})\end{array}$ & $\begin{array}{c}\text { HAZ } \\
\text { (retreating side) } \\
(\mu \mathrm{m})\end{array}$ \\
\hline 1 & 3.7 & 38.29 & 35.59 & 54.5 & 61.45 \\
3 & 9.02 & 23.1 & 32.05 & 19.6 & 34.09 \\
\hline
\end{tabular}

\section{SZ REGION, TMAZ REGION, AND HEAT AFFECTED ZONE (HAZ)}

The samples for microstructural examination, microhardness testing and grain size measurement were polished by following standard metallographic procedure and subsequently etched. The etched samples were observed under microscope with CCD camera to observe the microstructure of different zones. The images of the SZ region of first three experiments $(1,2$ and 3 ) are given in Figure 4(A), 4(B) and 4(C).

It was found that $\mathrm{SZ}$ region in sample-1 possessed smallest grains. The average grain size in SZ was measured to be $7.98 \mu \mathrm{m}$. The grains in the SZ region were equi-axial. The cooling with $\mathrm{LN}$ would have effectively cooled the tool and the heat could be effectively contained resulting smallest grain size in the SZ in case of sample which were cryogenically cooled. Crushed ice and rock salt experiment showed largest grains in the SZ in comparison to all other cooling conditions. The observed average grain size for sample-2 was $9.02 \mu \mathrm{m}$. The cooling medium in this case comprised of pieces of ice mixed with rock-salt. As the pieces were not fine and heat transfer could not be uniform resulting in relatively higher temperature in the SZ which resulted in the largest grain size. The third experiment was performed on ice water slush and it was in the consistency of the fine homogeneous slurry. The average grain size for sample-2 was found to be $8.52 \mu \mathrm{m}$. When relating to the hardness figures, it clear that as the grain sizes reduce, the hardness values increase. Taking experiment 1 as an example the average grain size was $7.98 \mu \mathrm{m}$. The hardness value in the same region was found to be $166.7 \mathrm{HV}$. While the particle size in the SZ region of sample 2 was found to be $9.02 \mu \mathrm{m}$ the hardness value was $154.67 \mathrm{HV}$. This is obvious as 
per Hall-Petch relationship wherein hardness values are inversely proportional to average grain size.

The TMAZ region of sample 1 showed very large grains as observed in Figure 4(D), 4(E), and 4(F). The average grain size was found to be $38.29 \mu \mathrm{m}$ on advancing side (AS) which was the largest amongst the other runs performed in that set of experiments. While the retreating side showed average grain size value of $35.59 \mu \mathrm{m}$. It appears from the grain size and the micrographs of the TMAZ that an insulating film of the nitrogen developed over the plate outside the shoulder could have reduced the heat transfer and the temperature would have been higher leading to higher grain size. Smallest of all the grains in the TMAZ were observed in sample-2. This may be attributed to the fact that the water constituent in the medium has mush higher evaporation temperature
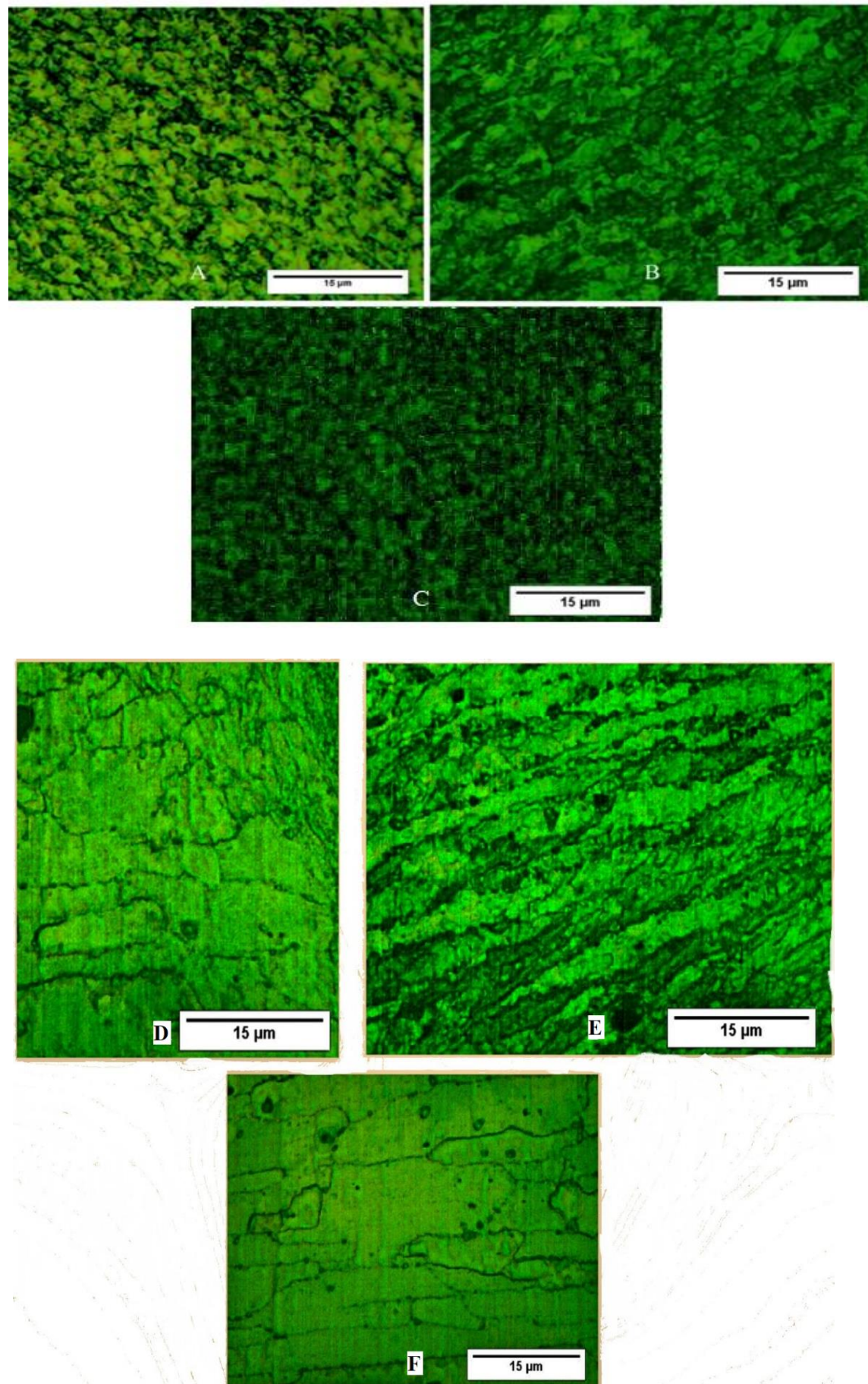

FIGURE 4. Stir zone for (A) experiment1, (B) experiment2, and (C) experiment3; TMAZ region of (D) sample1, (E) sample2 and (F) sample3, at 100X magnification 
and the lack of consistency due to present of pieces of rock-salt could have broken the insulating film of vapor and effectively enhanced the cooling of the plates. This would have effectively contained the grains coarsening in the TMAZ (and HAZ too). In the advancing side grain size was found to be $23.1 \mu \mathrm{m}$. While the retreating side showed average grain size value of $32.05 \mu \mathrm{m}$. TMAZ of sample 3 were also elongated but not as much coarsened as the first experiment. Average grain size was found to be $33.8 \mu \mathrm{m}$. The retreating side showed average grain size value of $30.12 \mu \mathrm{m}$. The grain sizes were lower than the liquid nitrogen experiment but higher than the crushed ice and rock salt experiment.

Unlike the TMAZ which is affected by the heat as well the induced strain produced due to stirring, the HAZ region is not influenced by the strain and it is solely affected by the heat transferred through conduction. Ideally, the microstructure of HAZ is somewhat similar to the base metal. Heat affected zone of samples 1, 2 and 3 in Figure 5.

Run 1 showed a very coarse grains in the HAZ, it is attributed to the same reason which is responsible for the TMAZ of sampel-1. The average grain size of the HAZ region of sample- 1 was found to be $54.5 \mu \mathrm{m}$. While the retreating side showed average grain size value of 61.45 $\mu \mathrm{m}$.

The average grain size in HAZ region for sample-2 was $19.6 \mu \mathrm{m}$ on advancing side (AS). While the retreating side (RS) showed average grain size value of 34.09- $\mu \mathrm{m}$. The sample-2 saw slight improvement in comparison to sample-1 in terms of grain size.

In case of sample- 3 the average grain size was found to be $34.04 \mu \mathrm{m}$ on the AS. While the RS showed average grain size value of $32.12 \mu \mathrm{m}$. This was much lower than the liquid nitrogen experiment.
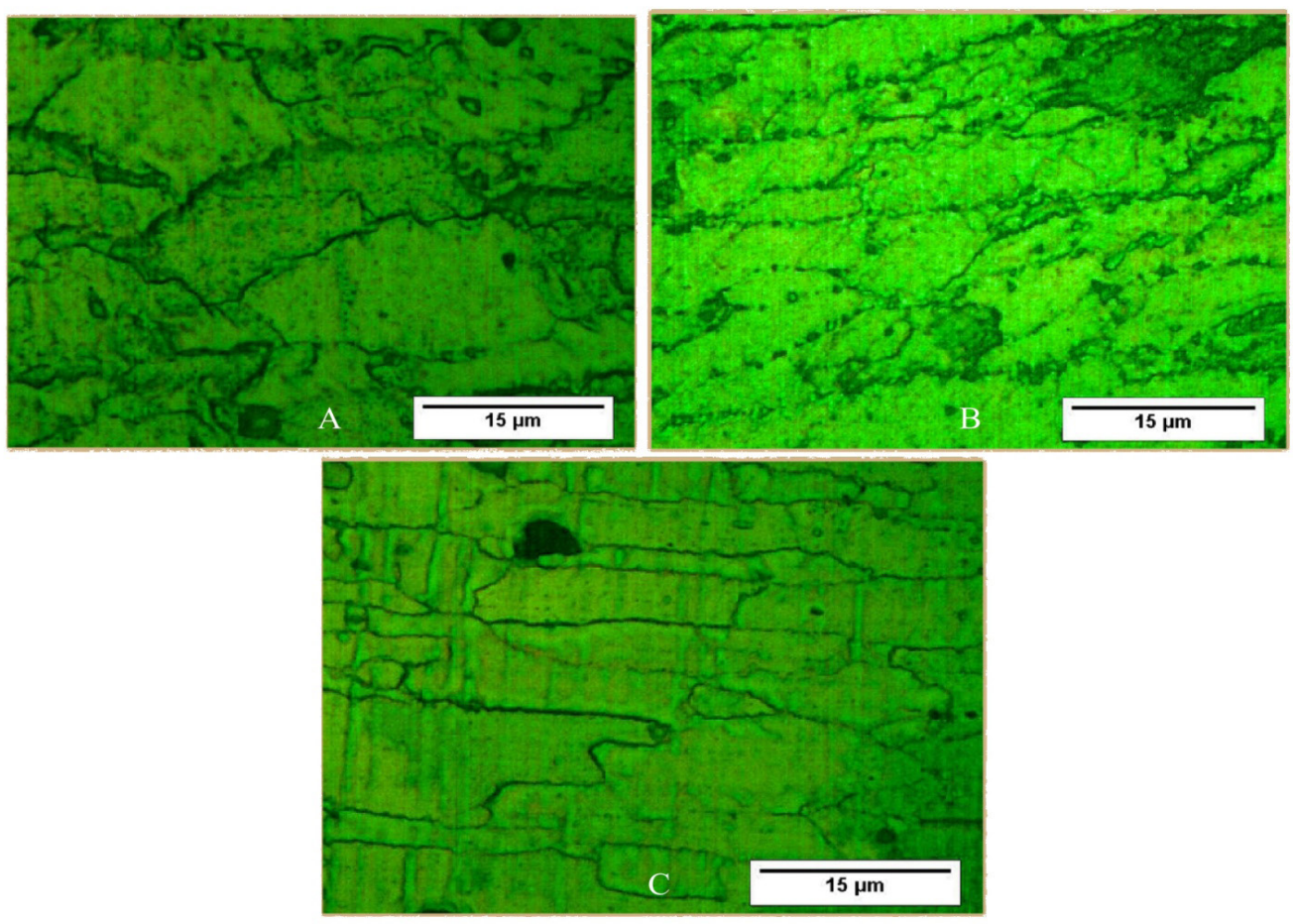

FIGURE 5. HAZ of (A) samples1, (B) sample2, and (C) sample3

Crushed ice and rock salt showed the lowest average grain size in HAZ region of the weld. Sample-3 showed somewhat similar microstructure as that of the base metal which is usually characteristic of the zone. In all such case, the rate of cooling has played a very important role. In case of cooling with LN the role of 
insulating film of nitrogen gas over the surface of plates would have reduced the cooling in regions of TMAZ, $\mathrm{HAZ}$, and BM. In case of rock-salt and ice mixture the most effective cooling would have occurred.

\section{MECHANICAL BEHAVIOR}

The joint efficiency for all the three cases was estimated by measuring the strength through tensile test by utilizing sub-size tensile test samples. The engineering ultimate tensile strength (UTS) and the elongation of the $\mathrm{BM}$ was $450 \mathrm{MPa} 13 \%$, respectively. Table 6 shows the mechanical properties of the welds.

The value of UTS for the sample (sample-1) cooled in liquid nitrogen was measured to be $252 \mathrm{MPa}$ which gave the joint efficiency as $56 \%$ as seen in Table 6 . In case of sample cooled with mixture of rock-salt and ice, the UTS was found to be highest at 353.1 MPa amongst the rest of the samples. As discussed in the preceding section that the cooling medium used in experiment-2 would have provided most effective cooling among all three cases and has resulted in the highest joint efficiency. In case of ice water slush, the engineering UTS value was found to be $294 \mathrm{MPa}$. It was discussed in the preceding section that the chances of formation of insulating film over the plate's surface would have adversely affected the cooling, whereas in case of water-ice slush the cooling although would have lower but more uniform. This joint strength and consequently the joint efficiency tool would have significantly affected by the effectiveness of the cooling medium and the order of joint efficiency related to the order of effectiveness of the cooling medium. The fractured tensile test samples are shown in Figure 6.

TABLE 6. Mechanical properties of the welds

\begin{tabular}{cccc}
\hline Run & $\begin{array}{c}\text { Engineering UTS } \\
(\mathrm{MPa})\end{array}$ & Joint efficiency & \multicolumn{2}{c}{ Elongation } \\
& 252 & $(\%)$ & 20.63 \\
\hline 1 & 352.1 & 56 & 23 \\
3 & 294 & 78.244 & 15.96 \\
\hline
\end{tabular}

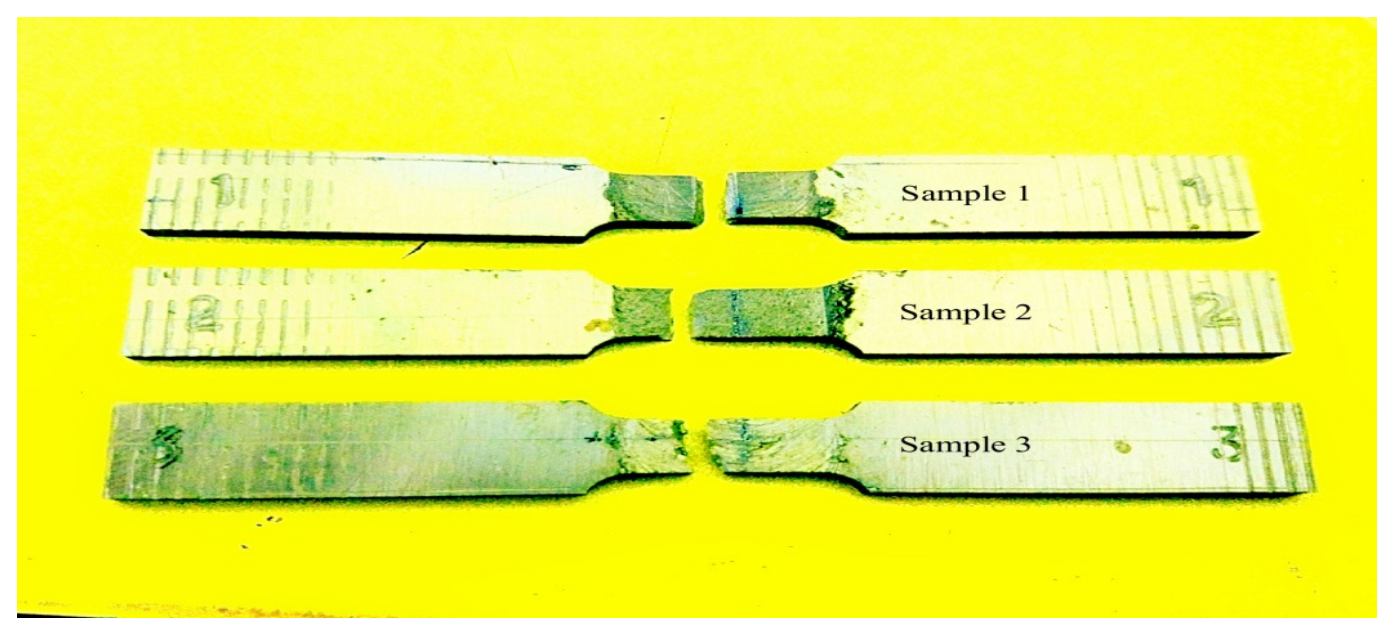

FIGURE 6. Fracture locations for samples 1, 2, and 3 


\section{CONCLUSION}

Based on the research work, the following conclusions were made. Among the three cooling conditions namely: cryogenic (by liquid nitrogen or $\mathrm{LN}$ ), rock-salt and ice mixture, and ice-water and ice slush, the most effective cooling was provided by mixture of rock-salt and ice followed by ice-water and ice slush and LN. The grain size was significantly small in in the SZ of welds made by using LN this is attributed to the fact that cooling of the tool effectively reduced the heat input in the stir zone. The grain size in TMAZ and HAZ was largest in case of the weld cooled by LN. This was attributed to the developments of an insulating film of the nitrogen above the plate's surface which could have adversely affected the cooling in the TMAZ and HAZ. The weld efficiencies of each of the samples 1, 2 and 3 were found to be $56 \%$, $78.244 \%$, and $65.33 \%$. The joint efficiency was found to vary in the order of effectiveness of cooling suggesting best overall cooling was obtained by rock-salt and ice mixture, followed by ice-water and ice slush and LN. A characteristic W shaped asymmetrical profile was found to bear distinct effect of in-process cooling. The welds with LN cooling although possess highest peak hardness in the stir zone but the lowest hardness in the TMAZ was obtained in this sample. The samples which were observed to possess stabilized micro-hardness the peak (less) and valley (was higher) of the characteristic W shaped plot was stabilized. The average micro-hardness values for the material in the SZ were observed to be 166.7, 154.67, and 157.54 for liquid nitrogen, crushed ice and rock-salt, and ice water slush experiments, respectively. While the TMAZ region showed average micro-hardness values to be $138.37,150.72$, and 148.68 for liquid nitrogen, crushed ice and rock-salt and ice water slush experiments, respectively. The average hardness values for the material in the HAZ region of the weld zone were observed to be $165.1,136.36$, and 161.56 for liquid nitrogen, crushed ice and rock-salt and ice water slush experiments, respectively.

\section{ACKNOWLEDGEMENTS}

The authors are grateful to the Raytheon Chair for Systems Engineering for funding.

\section{REFERENCES}

Baillie, P., Campbell, S.W., Galloway, A.M., Cater, S.R. \& McPherson, N.A. 2015. Friction stir welding of $6 \mathrm{~mm}$ thick carbon steel underwater and in air. Science and Technology of Welding and Joining 20(7): 585-593. doi: 10.1179/1362171815Y.0000000042.
Berg, L.K., Gjønnes, J., Hansen, V., Li, X.Z., Knutson-Wedel, M., Waterloo, G., Schryvers, D. \& Wallenberg, L.R. 2001. GpZones in $\mathrm{Al}-\mathrm{Zn}-\mathrm{Mg}$ alloys and their role in artificial aging. Acta Materialia 49(17): 3443-3451. https://doi.org/10.1016/ S1359-6454(01)00251-8.

Çam, G. \& İpekoğlu, G. 2017. Recent developments in joining of aluminum alloys. The International Journal of Advanced Manufacturing Technology 91(5): 1851-1866. doi: 10.1007/ s00170-016-9861-0.

Çam, G., İpekoğlu, G. \& Tarık Serindağ, H. 2014. Effects of use of higher strength interlayer and external cooling on properties of friction stir welded Aa6061-T6 joints. Science and Technology of Welding and Joining 19(8): 715-720. doi: 10.1179/1362171814Y.0000000247.

Çevik, B., Özçatalbaş, Y. \& Gülenç, B. 2016. Effect of tool material on microstructure and mechanical properties in friction stir welding. Materials Testing 58(1): 36-42. doi: $10.3139 / 120.110816$.

Fratini, L., Buffa, G. \& Shivpuri, R. 2010. Mechanical and metallurgical effects of in process cooling during friction stir welding of Aa7075-T6 butt joints. Acta Materialia 58(6): 2056-2067. https://doi.org/10.1016/j. actamat.2009.11.048.

Hofmann, D.C. \& Vecchio, K.S. 2007. Thermal history analysis of friction stir processed and submerged friction stir processed aluminum. Materials Science and Engineering: A 465(1): 165-175. https://doi.org/10.1016/j. msea.2007.02.056.

Hosseini, M. \& Danesh Manesh, H. 2010. Immersed friction stir welding of ultrafine grained accumulative roll-bonded Al alloy. Materials \& Design 31(10): 4786-4791. https://doi. org/10.1016/j.matdes.2010.05.007.

Huang, Y.X., Wan, L., Lv, Z.L., Lv, S.X., Zhou, L. \& Feng, J.C. 2016. Microstructure and microhardness of aluminium alloy friction stir welds with heat treatment. Science and Technology of Welding and Joining 21(8): 638-644. doi: 10.1080/13621718.2016.1152748.

Jacob, A., Maheshwari, S., Noor Siddiquee, A. \& Gangil, N. 2018. Improvements in strength and microstructural behaviour of friction stir welded 7475 aluminium alloy using in-process cooling. Materials Research Express 5(7): 076518. doi: 10.1088/2053-1591/aad0e6.

Jariyaboon, M., Davenport, A.J., Ambat, R., Connolly, B.J., Williams, S.W. \& Price, D.A. 2009. The effect of cryogenic $\mathrm{CO}_{2}$ cooling on corrosion behaviour of friction stir welded Aa2024-T351. Corrosion Engineering, Science and Technology 44(6): 425-432. doi: 10.1179/147842208X373173.

Kishta, E.E. \& Darras, B. 2016. Experimental investigation of underwater friction-stir welding of 5083 marinegrade aluminum alloy. Proceedings of the Institution of Mechanical Engineers, Part B: Journal of Engineering Manufacture 230(3): 458-465. doi: 10.1177/0954405414555560. 
Kumar, L., Yazar, K.U. \& Pramanik, S. 2019. Effect of Fusion and friction stir welding techniques on the microstructure, crystallographic texture and mechanical properties of mild steel. Materials Science and Engineering: A 754: 400-410. https://doi.org/10.1016/j.msea.2019.03.100.

Liu, X.C., Sun, Y.F., Nagira, T., Ushioda, K. \& Fujii, H. 2019. Experimental evaluation of strain and strain rate during rapid cooling friction stir welding of pure copper. Science and Technology of Welding and Joining 24(4): 352-359. doi: 10.1080/13621718.2018.1556436.

Liu, Z., Wang, Y., Ji, S. \& Li, Z. 2018. Effects of intense cooling on microstructure and properties of friction-stir-welded Ti-6al-4v alloy. Materials Science and Technology 34(2): 209-219. doi: 10.1080/02670836.2017.1366739.

Miura, T., Ueji, R. \& Fujii, H. 2018. Optimization of microstructure at $\mathrm{Ni}-\mathrm{C}$ steel joint by friction stir welding with $\mathrm{CO}_{2}$ cooling. Welding International 32(5): 338-344. doi: 10.1080/09507116.2017.1346831.

Mofid, M.A., Abdollah-zadeh, A. \& Malek Ghaini, F. 2012. The effect of water cooling during dissimilar friction stir welding of $\mathrm{Al}$ alloy to $\mathrm{Mg}$ alloy. Materials \& Design (1980-2015) 36: 161-167. https://doi.org/10.1016/j. matdes.2011.11.004.

Nelson, T.W., Steel, R.J. \& Arbegast, W.J. 2003. In situ thermal studies and post-weld mechanical properties of friction stir welds in age hardenable aluminium alloys. Science and Technology of Welding and Joining 8(4): 283-288. doi: 10.1179/136217103225011005.

Patel, V., Li, W., Wang, G., Wang, F., Vairis, A. \& Niu, P. 2019. Friction stir welding of dissimilar aluminum alloy combinations: State-of-the-art. Metals 9(3): 270.

Sakurada, D., Katoh, K. \& Tokisue, H. 2002. Underwater friction welding of 6061 aluminum alloy. Journal of Japan Institute of Light Metals 52(1): 2-6. doi: 10.2464/ jilm.52.2.

Sharma, C., Dwivedi, D.K. \& Kumar, P. 2012. Influence of in-process cooling on tensile behaviour of friction stir welded joints of Aa7039. Materials Science and Engineering: A 556: 479-487. https://doi.org/10.1016/j. msea.2012.07.016.

Weston, J. \& Wallach, R. 1998. Mechanical properties of laser welds in aluminium alloys. Paper presented at the International Conference; 7th, Joints in Aluminium: INALCO '98, Cambridge, UK.

Xu, N., Ueji, R. \& Fujii, H. 2015. Enhanced mechanical properties of $70 / 30$ brass joint by multi-pass friction stir welding with rapid cooling. Science and Technology of Welding and Joining 20(2): 91-99. doi: 10.1179/1362171814Y.0000000261.

Xu, W.F., Liu, J.H., Chen, D.L., Luan, G.H. \& Yao, J.S. 2012. Improvements of strength and ductility in aluminum alloy joints via rapid cooling during friction stir welding. Materials Science and Engineering: A 548: 89-98. https:// doi.org/10.1016/j.msea.2012.03.094.
Yi, D., Mironov, S., Sato, Y.S. \& Kokawa, H. 2016. Effect of cooling rate on microstructure of friction-stir welded Aa1100 aluminum alloy. Philosophical Magazine 96(18): 1965-1977. doi: 10.1080/14786435.2016.1185186.

Zhang, H.J., Liu, H.J. \& Yu, L. 2011. Microstructure and mechanical properties as a function of rotation speed in underwater friction stir welded aluminum alloy joints. Materials \& Design 32(8): 4402-4407. doi: https://doi. org/10.1016/j.matdes.2011.03.073.

Ashish Jacob \& Sachin Maheshwari

Division of Manufacturing Processes and Automation Engineering

Netaji Subhas University of Technology

(formerly Netaji Subhas Institute of Technology)

New Delhi-110078

India

Arshad Noor Siddiquee

Department of Mechanical Engineering

Jamia Millia Islamia (A Central University)

New Delhi-110025

India

Abdulrahman Al-Ahmari

Industrial Engineering Department

College of Engineering

King Saud University

Riyadh-11421

Saudi Arabia

Abdulrahman Al-Ahmari \& Mustufa Haider Abidi* Raytheon Chair for Systems Engineering

Advanced Manufacturing Institute

King Saud University

Riyadh-11421

Saudi Arabia

Sergey Konovalov

Department of Metals Engineering Material Science

Samara National Research University

Samara-443086

Russia

Xizhang Chen

School of Mechanical and Electrical Engineering

Wenzhou University

Zhejiang Province-325035

China

*Corresponding author; email: mabidi@ksu.edu.sa

Received: 5 January 2020

Accepted: 3 January 2021 